\title{
La ordenación sostenible del tiempo de trabajo: luces y sombras de las últimas reformas laborales
}

\author{
Ana Rosa Argüelles Blanco \\ Profesora titular de Universidad de Derecho del Trabajo y Seguridad Social \\ Universidad de Oviedo \\ anaargue@uniovi.es
}

Resumen: En el artículo se examinan los cambios introducidos, primero, por el Real Decreto 3/2012 y, tras su tramitación parlamentaria, por la Ley 3/2012 en diferentes instituciones relacionadas con la ordenación del tiempo de trabajo y el equilibrio con el tiempo propio de las personas trabajadoras. En particular, se valoran los aspectos positivos y negativos de las nuevas reglas sobre la distribución irregular de la jornada laboral, la realización de horas extraordinarias por los trabajadores a tiempo parcial, las reducciones de la jornada por motivos familiares $y$, finalmente, el derecho a vacaciones anuales retribuidas.

Palabras clave: Tiempo de trabajo, conciliación vida laboral y familiar, vacaciones, trabajo a tiempo parcial

Abstract: This article examines the changes made, first, by Royal Decree 3/2012 and, after undergoing the appropriate parliamentary procedure, by Law 3/2012 in various institutions in terms of the organization of work time and the balance with workers' own time. In particular, it assesses the positive and negative aspects of the new rules governing the irregular distribution of the working day, overtime by parttime workers, reductions in the working day for family reasons and, finally, the right to annual remunerated boliday.

Keywords: Work time, reconciliation of work and family life, boliday, part-time work 


\section{Flexibilidad en la ordenación del tiempo de trabajo y distribución irregular de la jornada ${ }^{1}$}

Potenciar la flexibilidad interna en las empresas para promover el empleo ha sido el mantra de las últimas reformas normativas y de los más recientes acuerdos interconfederales. Es preciso reconocer que esa línea de regulación se ha impuesto y reconocido como necesaria desde diversas orientaciones políticas e instancias sociales. En materia de tiempo de trabajo, la estrategia clave ha sido proporcionar a la dirección del personal herramientas para el fácil acomodo de la ordenación de las jornadas, los horarios y el ritmo de trabajo a las cambiantes necesidades organizativas y productivas. Se considera que así se favorece la competitividad y se reducen unos costes que, en el contexto de crisis económica, pueden conducir a la toma de decisiones de destrucción de empleos o, incluso, poner en peligro la supervivencia de la empresa. La Ley 3/2012, de 6 de julio, de medidas urgentes para la reforma laboral, resultado de la tramitación parlamentaria del Real Decreto-Ley 3/2012, de 10 de febrero, profundiza, en definitiva, un camino cuyo trazado marcaron la Ley 35/2010, de 17 de septiembre, y el Real Decreto-Ley 7/2011, de 10 de junio ${ }^{2}$. Esos textos juridificaron el concepto de flexibilidad interna e iniciaron la recomposición de las finalidades tradicionales de las normas laborales ${ }^{3}$. Avanzando unas reglas para las relaciones laborales que parecen olvidar que «toda revisión de la normativa laboral y toda ampliación de los poderes de gestión del empleador tienen como límite la dignidad del trabajador, incluido el desarrollo de su personalidad, que debe informar todo el conjunto del ordenamiento laboral» ${ }^{4}$.

Nadie ha puesto en cuestión la necesidad de reformas normativas y de proporcionar una mayor flexibilidad a las organizaciones empresariales. La discusión se centra, desde la perspectiva de la conveniente protección de otros legítimos derechos e intereses, en el diseño de las herramientas utilizadas y en el alcance que se otorga a las facultades patronales. Hay varios mecanismos que han puesto

\footnotetext{
1 El presente trabajo forma parte de los resultados de la investigación realizada en el marco del proyecto nacional $\mathrm{I}+\mathrm{D}$ «Gestión del tiempo en la empresa y la Administración pública: problemas jurídicos, impacto económico y riesgos sociales» (Ref. DER2010-21686-C01-01), financiado por el Ministerio de Ciencia e Innovación, en el que la autora es investigadora principal.

2 Un análisis sintético y clarificador de los contenidos de esas dos normas puede encontrarse en Ramírez Martínez, Juan Manuel (2012). «Algunos problemas interpretativos planteados por la regulación de la flexibilidad interna en las reformas laborales de 2010 y 2011». Actualidad Laboral, n. ${ }^{\circ}$, págs. 523-547.

3 Sobre la progresiva penetración del lenguaje económico en el articulado de las normas y la alteración de las funciones del derecho del trabajo que lleva aparejada esta tendencia, Vid. Valdés Dal-Ré, Fernando (2011). «La juridificación del concepto de flexibilidad interna». Relaciones Laborales, n. ${ }^{\circ} 22$, págs. 1-10.

4 Rodríguez-Piñero y Bravo-Ferrer, Miguel (2011). «La difícil coyuntura del Derecho del Trabajo». Relaciones Laborales, $\mathrm{n}^{\circ} 20$, pág. 9 .
} 
en manos de la empresa un gran poder para la ordenación flexible del tiempo de trabajo: la distribución irregular de la jornada a lo largo del año (art. 34.2 ET); la posible modificación de la jornada pactada en convenio, tanto estatutario como extraestatutario, aun cuando el período de consultas con los representantes de los trabajadores se haya cerrado sin acuerdo (art. 41.1.a y 41.3 y 6 ET); y la preferencia aplicativa de lo convenido a nivel de empresa sobre las reglas que pudiera fijar el convenio de sector (art. 84.2 ET).

Centrando el análisis en la distribución irregular de la jornada, ya la Ley 11/1994, de 19 de mayo, había modificado el artículo 34.2 del Estatuto de los Trabajadores para disponer que mediante convenio colectivo o, en su defecto, por acuerdo entre la empresa y los representantes de los trabajadores se podrá establecer la distribución irregular de la jornada a lo largo del año. Así se recogió en el texto refundido del año 1995. La distribución acordada deberá respetar en todo caso los períodos mínimos de descanso diario y semanal previstos en esta Ley. El origen de esa planificación irregular debía estar siempre en un pacto colectivo, sin que pudiera derivarse del individual y, menos aún, de una decisión unilateral del empresario. Se trata de un factor de flexibilidad muy importante que disminuye la importancia del trabajo extraordinario al pasar a ser solo el realizado por encima de la jornada correspondiente al módulo que se utilice para programar la distribución irregular. En la relación de supletoriedad establecida con la ley, el legislador situó los convenios colectivos y, en su defecto, los acuerdos de empresa en una posición privilegiada para regular el tiempo de trabajo 5 .

El artículo 9 del Real Decreto-Ley 3/2012, de 10 de febrero, de medidas urgentes para la reforma del mercado laboral, modificó el apartado 2 del artículo 34 del texto refundido de la Ley del Estatuto de los Trabajadores incorporando una previsión según la cual la empresa podrá distribuir de manera irregular a lo largo del año el 5 \% de la jornada dentro de aquellos límites. Una previsión similar había sido previamente ubicada en el artículo 85.3 por el Real Decreto-Ley 7/2011, quedando ahora en una situación más correcta puesto que con ella realmente no se establece el contenido de un convenio colectivo, sino una auténtica facultad empresarial en materia de jornada.

Aun reconociendo también ese derecho al empresario, las organizaciones firmantes del II Acuerdo para el Empleo y la Negociación Colectiva 2012, 2013 y 2014 (en adelante, AENC) quisieron que su alcance se sujetara a alguna ponderación de los intereses y las circunstancias concurrentes, vía negociación colectiva. Curiosamente, en su cuantificación habían ido más allá que el Gobierno en la fase

5 Roqueta Buj, Remedios (2012). «La flexibilidad interna», en Ángel Blasco Pellicer et alii (2012). La reforma laboral en el Real Decreto-Ley 3/2012. Valencia: Tirant lo Blanch, págs. 108-109, expone las principales opiniones doctrinales que, en ese sentido, se han manifestado. 
inicial de la reforma, como se verá. Considerando también que «los convenios deben incorporar como contenido mínimo la flexibilidad interna, particularmente la que opera en espacios temporales reducidos, para hacer frente a la coyuntura, como una potente herramienta para facilitar la adaptación competitiva de las empresas, favoreciendo una mayor estabilidad en el empleo, evitando el recurso al despido». Los agentes sociales afirmaron que el convenio colectivo es el espacio adecuado para ordenar el uso flexible de elementos como el tiempo de trabajo en un sentido complementario a las previsiones legales. $Y$ acordaron distinguir dos niveles: flexibilidad ordinaria y flexibilidad extraordinaria temporal.

Para la consecución de aquellos fines, el medio dispuesto como flexibilidad ordinaria en el tiempo de trabajo ha sido determinar que el contenido mínimo del convenio debería fijar el cómputo anual de la jornada y su distribución irregular. Los convenios sectoriales, especialmente los provinciales, deberán fijar las reglas generales de flexibilidad del tiempo de trabajo. Se afirma que se debiera considerar como principio general la distribución irregular de la jornada anual de trabajo a fin de evitar en lo posible las horas extraordinarias o la contratación temporal. En ese sentido, continúa el ANEC, los convenios deberían facilitar que el empresario pudiera distribuir irregularmente un $10 \%$ de la jornada máxima semanal o mensual (hasta el doble de lo que después fijó el legislador en el RDLey 3/2012), advirtiendo que con ello no se podrá modificar la jornada máxima anual, si bien sí la semanal o mensual e, incluso, los horarios diarios. Se advertía que serán los negociadores, en cada ámbito, los que concreten en más o en menos esa referencia porcentual.

Otra medida se suma en el AENC a la comentada: «Los convenios colectivos deberían posibilitar que el empresario disponga de una bolsa de cinco días (o 40 horas) al año que podrán alterar en la distribución prevista en el calendario anual». De nuevo, los negociadores podrán modificar esta referencia, en más o en menos, en función del ámbito de negociación.

Finalmente, el artículo 9 de la Ley $3 / 2012$ ha incrementado el porcentaje del $5 \%$ al $10 \%$ - como el AENC - y ha aprovechado para introducir una obligación empresarial para la comunicación de las decisiones de flexibilidad, pues «el trabajador deberá conocer con un preaviso mínimo de cinco días el día y la hora de la prestación de trabajo resultante de aquella». Aunque es un paso, con seguridad ese preaviso resulta insuficiente — ni siquiera son los siete días que exige para la realización de horas complementarias en el trabajo a tiempo parcial el art. 12.5 ET - y no elimina las incertidumbres a las que la población asalariada se enfrenta en relación con la disponibilidad de su tiempo propio. 
Los límites a la facultad de distribución se mantienen en los mismos términos. Así pues, se podrán sobrepasar en la distribución las cuarenta horas semanales, pero, como el artículo 34.3 no se ha modificado, el empresario tendrá que respetar el límite máximo de las nueve horas de jornada diaria ${ }^{6}$.

Debe ponerse de relieve que en esta segunda fase de la reforma de 2012 el legislador quizá ha querido apelar a que se haga un uso razonable de la facultad empresarial comentada, armonizándola con otros intereses igualmente dignos de protección jurídica y socialmente relevantes. En esa línea, el AENC había apuntado que «la flexibilidad del tiempo de trabajo debiera ir acompañada de garantías y seguridad para las personas, que les permitan compatibilizar el tiempo de trabajo y de conciliación». Así, la Ley 3/2012 modifica también el apartado 8 del artículo 34 - del que el Real Decreto-Ley no se había ocupado ni preocupadopara añadir que «se promoverá la utilización de la jornada continuada, el horario flexible u otros modos de organización del tiempo de trabajo y de los descansos que permitan la mayor compatibilidad entre el derecho a la conciliación de la vida personal, familiar y laboral de los trabajadores y la mejora de la productividad de las empresas» ${ }^{7}$.

Está bien que se recuerde expresamente esa necesidad, pues incluso en un contexto de crisis debiera apostarse por una gestión sostenible del tiempo de trabajo. Para que la previsión fuera eficaz, no obstante, debiera derivarse alguna consecuencia para el caso de que no se permitiese esa compatibilidad sin causa

6 Compartimos lo afirmado por Roqueta Buj, loc, cit., pág. 111.

7 Apartado añadido por la Ley Orgánica 3/2007, de 22 de marzo, para la igualdad efectiva de mujeres y hombres, y en el que se estableció lo siguiente: «El trabajador tendrá derecho a adaptar la duración y distribución de la jornada de trabajo para hacer efectivo su derecho a la conciliación de la vida personal, familiar y laboral en los términos que se establezcan en la negociación colectiva o en el acuerdo a que llegue con el empresario respetando, en su caso, lo previsto en aquélla». En supuestos planteados con anterioridad a esta previsión la jurisprudencia había interpretado que sin reducción de la jornada no existía apoyo legal para ejercer un derecho al cambio de horario y/o turno de trabajo. Esa posibilidad estaba reservada para el supuesto regulado en el artículo 37.5 ET; esto es, la reducción de la jornada por guarda legal de menor, cuidado de familiar hasta el segundo grado o persona con discapacidad. Baste mencionar, por todas las que la precedieron, la Sentencia del Tribunal Supremo de 19 de octubre 2009 (RJ 7606). En ella ya se advierte que tampoco en la normativa posterior se delega sin límites en el beneficiario de la conciliación la configuración del derecho contemplado en el artículo 34 del Estatuto de los Trabajadores. Sobre el particular, dos sentencias del Tribunal Constitucional, la 24/2011 y la 26/2001, ambas de 14 de marzo, se pronuncian en sentido aparentemente contradictorio. La primera niega el amparo insistiendo en la necesidad de que un pacto colectivo o individual dé cobertura a la persona trabajadora en su solicitud (en el supuesto, de adscripción permanente al turno de mañana). La segunda lo proporciona por entender que el juez ordinario no ponderó la dimensión constitucional del derecho en relación con la efectividad del derecho a la no discriminación por motivos familiares y, en su caso, las dificultades que pudiera ocasionar su pretensión en el funcionamiento de la empresa. Pero señala que no entra en sus competencias determinar si la concreta petición del recurrente se encontraba o no amparada por el artículo 34.8 ET. Deja claro, eso sí, que habría que valorar las circunstancias familiares y personales concretas — número de hijos, edad y situación escolar, situación laboral del cónyuge-, así como el régimen de trabajo en la empresa en cada caso para ver si la negativa empresarial es un obstáculo injustificado por permitir alteraciones como la interesada sin poner a la empresa en dificultades organizativas lo suficientemente importantes como para excluir tales modificaciones. 
objetiva y justificada ${ }^{8}$. Sin embargo, el legislador no lo ha hecho así, por lo que excluir que se haga un uso arbitrario de la facultad comentada queda inicialmente en manos del buen criterio del gestor que aplique la norma y, en último término, de la valoración y el control judicial, en el caso de llegar a plantearse la correspondiente demanda por la parte trabajadora'.

Pronto debiera haber nuevas medidas sobre el uso razonable de este derecho. Si el Gobierno ha asumido el compromiso de adoptar medidas dirigidas a promover la racionalización de horarios y la conciliación de la vida personal, familiar y laboral (disposición adicional decimoséptima Ley 3/2012) ${ }^{10}$, aquel no podría entenderse cumplido si la distribución irregular de la jornada pudiera conducir a una casi ilimitada alteración de los horarios con escaso margen de preaviso y sin razones objetivas para imponer al trabajador esa decisión.

\section{Comentario crítico de la nueva regulación del trabajo a tiempo parcial}

Otro de los aspectos relacionados con el tiempo de trabajo que ha resultado afectado por la reforma laboral de 2012 tiene que ver con las condiciones del trabajo a tiempo parcial. Manifestó la exposición de motivos del Real Decreto-Ley 3/2012 - y luego la de la Ley 3/2012 - que «el trabajo a tiempo parcial no sólo es un mecanismo relevante en la organización flexible del trabajo y en la adaptación del tiempo de trabajo a las necesidades profesionales y personales de los trabajadores, sino que es un mecanismo de redistribución del empleo». A la empresa le puede

8 De hecho, se ha considerado un evidente defecto de transposición de la Directiva 2003/88/CE, de 4 de noviembre de 2003, que el artículo 34.2 ET no relacione las causas justificativas de la distribución irregular, puesto que el artículo 19 de la norma europea sobre ordenación del tiempo de trabajo dispone que los Estados miembros «tendrán la facultad de permitir que, por razones objetivas, técnicas o de organización del trabajo, los convenios colectivos o acuerdos celebrados entre interlocutores sociales establezcan períodos de referencia que en ningún caso excederán de 12 meses». Cfr., sobre el particular, Monreal Bringsvaerd, Erik (2005). La jornada de trabajo: ley y convenio colectivo. Madrid, págs. 168 y sigs.

9 Como bien determina la Sentencia del Tribunal Supremo de 15 de diciembre de 1998 (RJ 10510), el precepto comentado autoriza la distribución irregular de la jornada a lo largo del año siempre que se respeten los períodos mínimos de descanso dispuestos legalmente. «Lo que no significa, que el empresario pueda hacer uso de esta facultad a su capricho, arbitrariamente o de manera irracional, como en general, no puede hacerlo con ninguna de las facultades en que se vertebra el poder de dirección de la actividad laboral. Ningún poder jurídico tolera ser ejercitado con abuso (artículo 7.2 Código Civil), cosa que sucede cuando su titular lo emplea, con daño de terceros, para fines ajenos a los que determinaron su concesión. La decisión empresarial de fijar el horario de trabajo, siempre habrá de fundarse en causas conectadas con la utilidad y necesidades del funcionamiento de la empresa, la concurrencia de las cuales es aspecto susceptible de someterse al control judicial, caso de discrepancia».

10 La citada disposición alude a que se adoptarían en el plazo de tres meses a partir de que elabore su informe la Subcomisión del Congreso de los Diputados para el análisis y estudio de la racionalización de horarios y la consiguiente conciliación de la vida personal, familiar y laboral, y de la corresponsabilidad. 
interesar este tipo de modelo contractual y ese interés también lo tienen algunas personas trabajadoras para las que la insuficiencia de otro tipo de mecanismos de conciliación de la vida personal, familiar y laboral, en su particular situación o para sus concretas necesidades, es un acicate para acceder a un empleo con jornada y retribución reducidas. También es cierto que el desempeño a tiempo parcial de un puesto podría propiciar el empleo compartido como fórmula de reparto de ese bien tan escaso en la actual situación económica que es el trabajo.

Los cambios afectan a la letra c) del artículo 12.4 del Estatuto de los Trabajadores. En el estadio normativo anterior las horas extraordinarias estaban expresamente prohibidas por esa disposición. La ampliación de la jornada solo podía conseguirla el empresario en el caso de que el contrato fuera de duración indefinida y de que se hubiera formalizado un pacto expreso con el trabajador para la realización de horas complementarias (art. 12.5 ET). Sin embargo, en la actualidad se permite la realización de horas extraordinarias, debiendo entenderse que ello cualquiera que sea la modalidad de contrato a tiempo parcial; esto es, tanto si fuera un contrato temporal como un contrato por tiempo indefinido. Advierte el legislador que la suma de horas ordinarias, complementarias y extraordinarias no podrá exceder el límite legal del trabajo a tiempo parcial tal y como la ley lo define. En otras palabras: no se admitirá que la realización de horas extras suponga, en la práctica, la desnaturalización del contrato a tiempo parcial por resultar finalmente igual la jornada a la del trabajador a tiempo completo comparable o a la máxima fijada en la ley o el convenio colectivo.

La posibilidad de que las personas trabajadoras a tiempo parcial puedan realizar horas extraordinarias tiene algunas consecuencias positivas. Desde luego, sirve al interés empresarial que se permita la prolongación de la jornada cuando lo requieran las necesidades productivas. También resultará atractiva para quienes deseaban acceder a un trabajo a tiempo completo, pero no encontraron un empleo de esa naturaleza. Por medio de las horas extraordinarias podrán incrementar - aunque no de forma estable - sus retribuciones y también mejorar su protección social, pues las realizadas se computarán para calcular las bases de cotización a la Seguridad Social, también por contingencias comunes, y las bases reguladoras de las prestaciones, que podrán ser ahora más elevadas ${ }^{11}$.

11 Remarca cómo esta regla se aparta del régimen común de la cotización por horas extraordinarias, recogido este año en el artículo 5 de la Orden ESS/184/2012, de 2 de febrero, Camps Ruiz, Luis Miguel (2012). «Contratación, formación y empleo en el RDL 3/2012», en Ángel Blasco Pellicer et alii (2012). La reforma laboral en el Real Decreto-Ley 3/2012. Valencia: Tirant lo Blanch, pág. 75. Sobre esta ventaja y su alcance, Vid. también Luján Alcaraz, J., González Díaz, F. A. y Ríos Mestre, J. M. (2012). «Medidas para el fomento de la contratación indefinida y la creación de empleo», en Faustino Cavas Martínez (coord.) (2012). La reforma laboral de 2012. Análisis del Real Decreto-Ley 3/2012, de 10 de febrero, de medidas urgentes para la reforma del mercado laboral. Murcia: Ediciones Laborum, págs. 115-116. 
Desde un análisis con perspectiva de género también es posible encontrar alguna ventaja a la reforma. No se elimina, pero se puede sortear un motivo de la brecha salarial entre mujeres y hombres, visible al cruzar las estadísticas sobre la distribución por sexos entre contratación a tiempo completo y a tiempo parcial con los diferentes importes establecidos para las horas extraordinarias y las complementarias. Téngase en cuenta que es práctica habitual que el convenio colectivo fije un valor superior para la hora extraordinaria, mientras que el de la complementaria sería el de la hora ordinaria, pese a ser mecanismos de flexibilidad en el uso del tiempo de trabajo muy similares en la práctica. Por ello, se ha puesto de manifiesto que la prohibición de realizar horas extraordinarias en el marco de un contrato a tiempo parcial entrañaba ciertos riesgos para la igualdad de trato entre mujeres y hombres ${ }^{12}$, máxime cuando España es uno de los países europeos con mayor segregación ocupacional ${ }^{13}$.

Sin desconocer estas posibles ventajas de la nueva regulación, hay que poner de manifiesto que la reforma no ha atajado determinados peligros. Ni se han establecido cautelas para la exigencia de horas extraordinarias por parte de las organizaciones empresariales, ni se ha tenido en cuenta la diversidad de situaciones personales que conducen a una contratación a tiempo parcial. Desde el punto de vista de la búsqueda del equilibrio entre las necesidades empresariales de tiempo de trabajo y los derechos sociales al tiempo propio, lo que preocupa es que será difícil controlar si serán realizadas de forma voluntaria, voluntariedad que no puede olvidarse que constituye uno de sus elementos definidores y esenciales ${ }^{14}$. A nadie escapa que la vigilancia del cumplimiento de la normativa laboral en materia de jornada siempre ha sido dificultosa por los dilatados lapsos de tiempo en que se permite la compensación de las horas de más realizadas, sea por retribución o por descanso compensatorio.

La suma de jornada ordinaria, extraordinaria y, en caso de haberla pactado, complementaria puede acabar convirtiéndose en una pesadilla para la concilia-

12 Véase la acertada reflexión sobre el valor de la hora extraordinaria y su comparación con el valor de la hora complementaria en el contrato a tiempo parcial de Ezquerra Escudero, Luis (2006). Tiempo de trabajo: duración, ordenación y distribución. Barcelona: Editorial Atelier, pág. 435.

13 Sobre esta segregación, así como sobre las diferencias entre las ganancias medias asociadas a la realización de jornada parcial o jornada completa que evidencian una penalización de la primera, $V$ id. el interesante estudio de Denia Cuesta, Alfonsa y Guilló Fuentes, María Dolores (2010). «Género y jornada parcial en España: segregación y empleo involuntario», en Antonio Villar (dir.) (2010): Mujeres y mercado laboral en España. Cuatro estudios sobre la discriminación salarial y la segregación laboral. Bilbao: Editorial Brief-Fundación BBVA, págs. 49-81.

14 Vid., por todos, Ezquerra Escudero, Luis (2006). Tiempo de trabajo..., óp. cit., pág. 437-439, con detallada referencia de la doctrina y jurisprudencia que de forma clara así lo ha afirmado. Si la propia esencia del contrato de trabajo está basada en la voluntariedad de las partes, también esa voluntariedad debiera concurrir en lo que se adiciona a la prestación básica, como es el caso de las horas extraordinarias. Debe haber un pacto sobre el trabajo adicional al no ser admisible que este suponga trabajo forzoso. 
ción de la vida personal, familiar y laboral. En general, porque habrá una gran incertidumbre sobre cuándo se producirá una exigencia de mayor tiempo de trabajo y, en especial, porque para algunas personas $-y$ debido al persistente reparto tradicional de roles en muchas familias, principalmente para las mujeres - la nueva regla puede privar de eficacia al modelo que buscaron precisamente porque les permitía continuar con su carrera profesional y atender a sus responsabilidades de otro orden. Cuando se ha calculado estar con la persona a cargo - en aplicación de la jornada ordinaria-, resulta que quizá no sea posible porque se solicita la permanencia en el puesto con pocos días de antelación.

En suma, la coexistencia de la posibilidad de realizar horas extraordinarias con la de pactar horas complementarias no parece una buena medida, máxime cuando la parte empresarial también dispone para con los trabajadores a tiempo parcial de los mismos mecanismos para modificar la jornada y los horarios que al inicio han sido apuntados. Parece que entre las iniciativas de actuación que aparecían en los documentos del Gobierno que fueron el preludio de la reforma de 2010 estaba ya la inclusión de la posibilidad de realizar horas extras en el trabajo a tiempo parcial, pero ello como compensación a la eliminación de las complementarias, propuesta como consecuencia del uso abusivo de estas últimas ${ }^{15}$. Pues bien, esta actuación finalmente eliminada hubiera sido, en nuestra opinión, el buen camino, por lo que debiera recuperarse esa segunda idea.

El debate está servido, así pues, entre los defensores de las posibilidades de pactar jornadas parciales con mayores márgenes de flexibilidad y elasticidad - el llamado trabajo a tiempo parcial «a la carta»- y quienes preconizan (preconizamos) una mayor garantía y certeza para la parte trabajadora sobre su horario y su distribución ${ }^{16}$.

Por los motivos anteriormente manifestados, habrá que cuidar que en la aplicación de la nueva regla se respete que faculta únicamente al empresario para ofrecer las horas extraordinarias, pero quedando a expensas de la aceptación del trabajador. Sin que quepa ignorar las consecuencias que puede tener dejar al libre juego de la autonomía individual la regulación de condiciones de trabajo cuando uno de los contratantes, el trabajador, se encuentra — además de inmerso en un contexto de crisis económica, que lo es para ambos - en una posición negociadora más débil que la contraparte empresarial ${ }^{17}$.

15 Dan cuenta de esta y otras líneas de actuación inicialmente previstas, así como del contenido de las enmiendas presentadas sobre este contrato por otros grupos parlamentarios, Luján Alcaraz, J., González Díaz, F. A. y Ríos Mestre, J. M. (2012). «Medidas para el fomento de la contratación indefinida y la creación de empleo», óp. cit., págs. 108-109.

$16 \mathrm{Da}$ cuenta de las distintas posiciones doctrinales en torno a esta cuestión Benavente Torres, María Inmaculada (2005). El trabajo a tiempo parcial. Sevilla: Consejo Económico y Social de Andalucía, págs. 184-197.

17 Como advierten, para el caso del pacto de horas complementarias, Monereo Pérez, J. L.y Gorelli Hernández, 
Sería deseable, a nuestro juicio, que la introducción de las horas extraordinarias en el trabajo a tiempo parcial hubiera venido acompañada de la supresión del pacto de horas complementarias. Pero también que las garantías que acompañaban a este pacto se hubieran establecido ahora para la exigencia de trabajo extraordinario, especialmente para las personas que accedieron a ese contrato vigente la prohibición de horas extraordinarias, con la expectativa, en suma, de que el tiempo propio que se reservaban continuaría siéndoles respetado. La posibilidad de solicitar la realización de horas extraordinarias también tendría que someterse a la consecución de un pacto escrito como garantía del equilibrio de intereses entre las partes que accedieron a esa contratación.

Por último, es preciso señalar que si realmente se quisiera favorecer el empleo potenciando que este fuera compartido, como sugieren las sucesivas exposiciones de motivos de las normas de reforma, permitir de forma redundante la realización de horas extraordinarias y complementarias no es el camino. Todo lo contrario: admitiendo en los actuales términos la realización de horas extraordinarias, no se promueven nuevas contrataciones, sino que terminará por eliminarse su necesidad.

\section{Fortalezas y debilidades del nuevo régimen jurídico de las reducciones de la jornada laboral}

A la gestión y ordenación del tiempo de trabajo en las organizaciones productivas les afectan muy claramente los términos en que se reconozcan a las personas trabajadoras los derechos para la conciliación de su vida personal y profesional. En la determinación de su régimen jurídico y en su aplicación surgen conflictos de intereses - más tiempo de trabajo, más tiempo propio- manifestados en unos ámbitos por los sujetos de la relación laboral, y en otros por los agentes sociales que los representan o por las diferentes sensibilidades políticas. Es preciso por ello examinar cómo ha afectado la reforma laboral a las normas que regulan algunos de esos derechos. Las modificaciones operadas en su titularidad y condiciones de ejercicio son muy significativas pese a que no aparezcan recogidas en la parte nuclear del Real Decreto-Ley 3/2012 — tampoco en la de la Ley $3 / 2012-$, sino en sus disposiciones adicionales.

En primer lugar, se afecta a la reducción de la jornada por lactancia de un menor de nueve meses contemplada en el apartado 4 del artículo 37 del Estatuto de los Trabajadores. En líneas generales puede decirse que la reforma ha traído

J. (2009). Tiempo de trabajo y ciclos vitales. Estudio crítico del modelo normativo. Granada: Editorial Comares, pág. 182. 
consigo una mejor configuración legal. Por una parte, porque por fin se reconoce como un derecho de titularidad indistinta para mujeres y hombres. Ha habido que esperar muchos años para que se corrigiese por fin esta anomalía, salvada en determinados ámbitos por cláusulas más adecuadas de los convenios colectivos ${ }^{18}$. Incluso tras promulgarse la Ley 3/2007, de 22 de marzo, para la igualdad efectiva entre mujeres y hombres, incomprensiblemente se reconocía a «las trabajadoras, por lactancia de un hijo», por más que luego se dispusiera que podría ser disfrutado indistintamente por la madre o el padre en caso de que ambos trabajen. Estas previsiones no se compaginaban con el «reparto equilibrado de responsabilidades familiares» que postula el artículo 44.2 de la propia Ley de Igualdad. Porque si la madre no trabajaba, el resultado era que el padre resultaba en todo caso privado de la posibilidad de ejercitar el derecho, lo que constituía una clara discriminación por razón de sexo. Y, desde luego, no favorecía los acuerdos entre la pareja para decidir quién accedería a disfrutarlo, al primar la decisión de la trabajadora por considerarla titular natural y legal del derecho.

Con la nueva redacción del precepto ya no hay una titularidad originaria única de la mujer, ni siquiera preferente ${ }^{19}$, con lo que nuestro ordenamiento laboral se ajusta a la doctrina fijada por la Sentencia del Tribunal de Justicia (Sala Tercera) de la Unión Europea de 1 de julio de 2010, dictada en el asunto Roca Álvarez y Sesa Start España ETT, S. A. En ella el Tribunal declaró que el artículo 2, apartados 1, 3 y 4, y el artículo 5 de la Directiva 76/207/CEE del Consejo, de 9 de febrero de 1976, relativa a la aplicación del principio de igualdad de trato entre hombres y mujeres en lo que se refiere al acceso al empleo, a la formación y a la promoción profesionales y a las condiciones de trabajo, deben interpretarse en el sentido de que se oponen a una medida nacional que prevé que las mujeres que sean madres de un niño y que tengan la condición de trabajadoras por cuenta ajena pueden disfrutar de un permiso, según varias modalidades, durante los nueve primeros meses siguientes al nacimiento de ese hijo, mientras que los hombres que sean padres de un niño y que tengan la condición de trabajadores por cuenta ajena solo pueden disfrutar del citado permiso cuando la madre de ese niño también tenga la condición de trabajadora por cuenta ajena.

18 Sobre estas cláusulas, Vid. Cabeza Pereiro, Jaime (2008). «Los derechos de conciliación de la vida personal, familiar y laboral de las personas trabajadoras», en José Fernando Lousada Arochena (coord.) (2008). El principio de igualdad en la negociación colectiva. Madrid: Ministerio de Trabajo e Inmigración-Comisión Consultiva Nacional de Convenios Colectivos, pág. 268.

19 Como destacan Sánchez Trigueros, C. y Fernández Orrico, F. J. (2012). «Conciliación de la vida familiar y laboral, apoyo al autoempleo y otras medidas», en Faustino Cavas Martínez (coord.) (2012). La reforma laboral de 2012. Análisis del Real Decreto-Ley 3/2012, de 10 de febrero, de medidas urgentes para la reforma del mercado laboral. Murcia: Ediciones Laborum, pág. 298, que indican que tampoco aparece una fórmula para solucionar posibles concurrencias. 
Por otra, la relación de filiación con el menor deja de ser una exigencia, contemplando también la relación de dependencia que existe entre aquel y la persona trabajadora con motivo de su acogimiento. Ello está en consonancia con lo previsto para otros derechos vinculados a la misma finalidad, que es, en definitiva, propiciar un tiempo para el acompañamiento del recién nacido que se tiene a cargo. La disposición final primera del Real Decreto-Ley 3/2012 modificó el artículo 37.4 para reconocer el beneficio «en los supuestos de nacimiento de hijo, adopción o acogimiento de acuerdo con el artículo 45.1.d) de esta Ley», lo que alude indirectamente a los casos en que este último sea preadoptivo, permanente o simple - aunque sea provisional - de conformidad con el Código Civil o las leyes civiles de las comunidades autónomas que lo regulen. Siempre, para el supuesto del simple, que su duración no sea inferior a un año, por exigencia de la misma norma. La duración del permiso, como estaba ya previsto para el caso del nacimiento o la adopción, se incrementará proporcionalmente si el acogimiento fuese múltiple.

Hay un aspecto, no obstante las mejoras introducidas en el régimen jurídico del derecho, que constituye aún un punto débil desde el punto de vista social. Se manifiesta que es un derecho individual, pero, a nuestro juicio, aún no lo es en puridad. Como hemos indicado antes, la titularidad es ahora indistinta, pero el derecho se reconoce más al grupo familiar que al individuo. Ello porque «sólo podrá ser ejercido por uno de los progenitores en caso de que ambos trabajen». La fórmula parece demasiado restrictiva y, de nuevo, no promueve la corresponsabilidad. Hubiera sido más apropiado limitar el ejercicio simultáneo en términos ya conocidos y ensayados, empleando la formulación de que «si dos trabajadores de la misma empresa generasen este derecho por el mismo sujeto causante, el empresario podrá limitar su ejercicio simultáneo por razones justificadas de funcionamiento de la empresa». Así se prevé en el mismo precepto para otras causas de reducción de la jornada (art. 37.5 in fine) o para el caso de la excedencia por cuidado de familiares (art. 46.3 ET). Es verdad que se trata de figuras en las que el empresario no carga con la retribución del trabajador durante ese período, lo que supone una esencial diferencia. Pero también que el resultado hubiera sido también un mayor equilibrio entre la atención de las necesidades productivas y las sociales. Al limitarlo «en caso de que ambos trabajen» sin más precisión, parece que el límite opera incluso cuando lo hagan bajo regímenes distintos, laboral y funcionarial. En cuanto a los acuerdos en la familia para el ejercicio compartido sucesivo, no simultáneo, ya hay autores que, yendo más allá de la aplicación automática y literal de la disposición, postulan la posibilidad de un cambio en el 
sujeto de disfrute siempre que sea razonable, no se cometan abusos de derecho o se actúe de mala fe, y, por supuesto, se preavise a los empresarios afectados ${ }^{20}$.

En segundo lugar, otro derecho afectado por la reforma es la reducción de la jornada por guarda legal de un menor de ocho años o de una persona con discapacidad. Los cambios introducidos solo han tenido en cuenta la conveniencia de las organizaciones productivas y han introducido recortes significativos en las posibilidades de ejercicio por parte de las personas trabajadoras, sin considerar los intereses no solo personales, sino también sociales que subyacían en la amplitud con que antes estaba diseñado.

Se menciona expresamente ahora que la reducción de la jornada - entre un octavo y la mitad, con disminución proporcional del salario- será «diaria», rompiendo con la interpretación judicial extensiva sobre las posibilidades para la persona trabajadora de concretar cómo operaría esa reducción sobre su tiempo de trabajo. Esta se ha sostenido a partir de la Sentencia del Tribunal Constitucional TC 3/2007, de 15 de enero, a la que siguieron otras de diferentes órganos judiciales en las que se resolvieron favorablemente las demandas de la parte trabajadora de excluir varios de los días laborables de la semana en aplicación de la reducción de jornada.

El Alto Tribunal destacó en la mencionada sentencia la dimensión constitucional del derecho a la conciliación. Por ella, dijo, el juez debe ponderar en cada caso las circunstancias concurrentes y si denegar la reducción en los términos solicitados constituiría o no un obstáculo para la compatibilidad entre vida familiar y laboral. Sin embargo, con la actual redacción la jurisdicción ordinaria no podrá entrar en estas consideraciones, pues está claro que el legislador ha querido evitar la concentración del tiempo que la reducción de jornada deja libre al trabajador en determinados días de la semana. Desde luego, se reducen las fórmulas de corresponsabilidad para que dos miembros de una misma unidad familiar que trabajen en distintas empresas apliquen la reducción y compaginen su tiempo de trabajo y su tiempo de cuidados; se podrán repartir las horas de cada día, pero no los días de la semana.

Debe precisarse, para evitar malentendidos, que la reforma y el límite comentados no alcanzan a los supuestos — regulados en otros apartados del mismo artículo- en que la reducción de la jornada se haya solicitado para el cuidado de otro familiar hasta el segundo grado o de un menor afectado por cáncer u otra enfermedad grave que implique un ingreso hospitalario de larga duración. Tampoco debieran aplicarse a las situaciones de reducción de jornada por guarda de un menor preexistentes, que deberían continuar rigiéndose por la normativa

20 En este sentido se han pronunciado Sánchez Trigueros, C. y Fernández Orrico, F. J. (2012). «Conciliación de la vida familiar y laboral...», loc. cit., pág. 300. 
vigente en el momento de iniciarse el disfrute, pues es entonces cuando se aplica la regla por la que se determina a quién corresponde - y en qué términos- la concreción horaria.

También hay que poner de relieve que la comentada disposición final primera ha modificado el apartado 6 del artículo 37 del Estatuto de los Trabajadores, relativo a la concreción horaria y la determinación del período de disfrute del permiso de lactancia y de la reducción de la jornada por esta causa y por las previstas en el apartado 5 del precepto, a las que justamente antes se ha aludido (cuidado del menor de ocho años, del familiar hasta el segundo grado y del menor hospitalizado por enfermedad grave durante un largo período). Esa concreción horaria corresponderá al trabajador, pero puede estar condicionada. Ello porque «los convenios colectivos podrán establecer, no obstante, criterios para la concreción horaria de la reducción de la jornada, en atención a los derechos de conciliación de la vida personal, familiar y laboral del trabajador y las necesidades productivas y organizativas de las empresas». Se pone en el mismo plano la alusión a unos y otros intereses, los familiares y los empresariales, aunque de forma sucesiva, dejando que sean los sujetos legitimados para negociar quienes los ponderen y prioricen.

Los agentes sociales habrán de concretar qué causas justifican que la empresa posponga el ejercicio del derecho en los términos solicitados o pueden permitir la acumulación del tiempo reducido para disfrutarlo en períodos de referencia superiores al día. Seguramente el legislador ha buscado la complicidad de la autonomía colectiva para conseguir introducir como criterio relevante para la concreción del tiempo de ejercicio de tales derechos la protección del interés empresarial, olvidando que el valor jurídico que protege esa regulación es el interés del menor o el interés del familiar ${ }^{21}$.

No pensamos, sin embargo, que la nueva regla introducida en el apartado 5 deba considerarse como derecho necesario absoluto, sino que es susceptible de modificarse por el convenio en beneficio de la parte trabajadora y que esta debiera ser la tendencia en la negociación colectiva. Desde luego, los negociadores debieran considerar las diferentes necesidades de conciliación de la vida profesional y familiar de las personas trabajadoras para tratar esos derechos - como el de adaptar la distribución de la jornada sin reducción de esta (art. 34.8 ET) atendiendo a su relevancia constitucional y restableciendo su prevalencia ${ }^{22}$. Sosla-

21 Como subraya Molina Navarrete, Cristóbal (2012): «De las reformas laborales a un nuevo, e irreconocible, Estatuto del Trabajo Subordinado». Estudios Financieros. Revista de Trabajo y Seguridad Social, n. 348, págs. 78-79, sugiriendo que el legislador no se ha atrevido a introducir directamente límites por los problemas de constitucionalidad que podrían derivarse.

22 Destacan esa prevalencia constitucional Rodríguez-Piñero y Bravo-Ferrer, Miguel, Valdés Dal-Ré, Fernando y Casas, María Emilia (2012). «La nueva reforma laboral». Relaciones Laborales, n. o 5, págs. 10-11. 
yando, además, los inconvenientes que la modificación legal puede plantear a las propias empresas y que el legislador no ha tenido en cuenta, pues como alguna autora ha destacado, con la reforma ha aparecido un motivo más para el denominado «riesgo moral»; esto es, aquel por el que determinadas situaciones de incapacidad temporal tienen su origen no en la enfermedad, sino en la imposibilidad manifiesta de asistir a asuntos personales o atender a necesidades familiares por la excesiva rigidez de la jornada.

Por otro lado, el plazo de preaviso de quince días con que el trabajador debía comunicar al empresario el retorno a la jornada ordinaria se convierte ahora en un mínimo que puede ser incrementado por el convenio colectivo aplicable, exigiéndose también la advertencia previa, en el plazo fijado por la ley o el convenio, para determinar en qué fecha se iniciará la reducción de jornada por lactancia o por guarda legal. En contrapartida, se señala que no será preciso respetarlo en caso de fuerza mayor.

Hay que preguntarse cómo se compagina este derecho con las novedades introducidas en cuanto al descuelgue del convenio colectivo (art. 82.3 ET) o en la modificación sustancial (art. 41.1.c ET). El empresario no debiera poder por estas vías dejar sin efecto lo convenido y/o aplicado inicialmente por la persona trabajadora. Iniciada una situación, deben respetarse, como garantía del derecho a la conciliación, los términos en que se concretó la reducción. Y en relación con las situaciones pro futuro, si hay descuelgue de las cláusulas convencionales entre las que estén las relativas a la reducción de la jornada por guarda legal, hay que entender que sería la persona trabajadora quien recuperaría la facultad de concreción con, eso sí, la limitación de que sea una reducción diaria.

Para concluir, debe siquiera apuntarse que la Ley 3/2012 (disposición final decimoquinta) ha introducido en el artículo 37 del Estatuto de los Trabajadores algunas previsiones sobre los derechos laborales de las víctimas del terrorismo que, en síntesis, suponen atribuir a dichas víctimas los derechos que tenían reconocidas las mujeres víctimas de violencia de género.

\section{Incidencia de la paternidad y la incapacidad temporal en el derecho a vacaciones}

Deben comentarse también los cambios introducidos en 2012 en el régimen jurídico de las vacaciones anuales retribuidas. Aunque no estaba entre sus objetivos, la reforma se ha aprovechado para corregir algunas deficiencias observadas en el régimen jurídico del derecho y acomodarlo a la doctrina judicial que se había 
sentado en los últimos años en la interpretación del artículo 38.3 del Estatuto de los Trabajadores. Con ello, en líneas generales, se perfecciona la garantía para la persona trabajadora de que otros legítimos derechos - a la conciliación de la vida laboral con la familiar o a la recuperación de la salud - no interfieran en el disfrute de las vacaciones y la finalidad a la que estas sirven.

Por una parte, se salva una omisión inexplicable tras haber incorporado la Ley de Igualdad como causa de suspensión del tiempo de trabajo el permiso por paternidad. Esa Ley incorporó una previsión sobre el derecho de las personas trabajadoras a disfrutar las vacaciones en fecha distinta de la de la incapacidad temporal derivada del embarazo, parto o lactancia natural, o de la fecha de la suspensión del contrato de trabajo por maternidad, prevista en el artículo 48.4 del Estatuto. Pero el derecho a trece días ininterrumpidos de suspensión del contrato por nacimiento de hijo, adopción o acogimiento se estableció en el artículo 48 bis, precepto que no mencionaba el artículo 38, por lo que a partir de la literalidad de la norma no podía defenderse que se protegiera del mismo modo. Finalmente, la nueva redacción sí alude a aquella disposición, por lo que el permiso por paternidad se añade a las causas en las que se podrá instar a la empresa a que fije una fecha alternativa para las vacaciones. Se establece así con carácter general un derecho que solo en algunos ámbitos los convenios colectivos de referencia habían hecho extensivo para el caso de las suspensiones por paternidad ${ }^{23}$.

Por otra, se acomoda el precepto a la doctrina revisada del Tribunal Supremo en materia de incapacidad temporal y vacaciones que parte de la Sentencia de 24 de junio de $2009^{24}$. Doctrina que acoge la interpretación de nuestra norma a la vista del derecho de la Unión Europea fijada por el Tribunal de Justicia de las Comunidades Europeas (Gran Sala) en Sentencia de 20 de enero de 2009, dictada en el asunto Gerhard Schultz-Hoff y otros. En esta resolución, y en otras que la siguieron ${ }^{25}$, se determinó que el artículo 7 apartado 1 de la Directiva 2003/88 debe interpretarse en el sentido de que se opone a disposiciones o prácticas na-

23 Caso del Convenio colectivo para las empresas de perfumería y afines, el Convenio Marco estatal de acción e intervención social o el Convenio del sector de intervención social de Madrid, según informaba Cabeza Pereiro, Jaime (2008), «Los derechos de conciliación de la vida personal, familiar y laboral de las personas trabajadoras», loc. cit., pág. 245, manifestando el interés de esas cláusulas.

$24 \mathrm{Al}$ criterio mantenido por el Tribunal Supremo a partir de la Sentencia de 24 junio de 2009 (2009/4286), contrario al de otras sentencias precedentes, se ha sumado después la de 15 noviembre de 2010 (RJ 2010/9146).

25 Como la Sentencia del 10 de septiembre de 2009, asunto Vicente Pereda y Madrid Movilidad, S. A., en que el Tribunal de Justicia manifestó que el artículo 7 apartado 1 de la Directiva 2003/88/CE del Parlamento Europeo y del Consejo, de 4 de noviembre de 2003, relativa a determinados aspectos de la ordenación del tiempo de trabajo, debe interpretarse en el sentido de que se opone a disposiciones nacionales o convenios colectivos que establezcan que un trabajador que se encuentre en situación de incapacidad temporal durante el período de vacaciones anuales fijado en el calendario de vacaciones de la empresa en la que está contratado no tiene derecho, una vez dado de alta médica, a disfrutar de sus vacaciones anuales en un período distinto del fijado inicialmente, en su caso fuera del período de referencia de que se trate. 
cionales que prevean que el derecho a vacaciones anuales retribuidas se extingue al finalizar el período de devengo de estas y/o el período de prórroga fijado por el Derecho nacional, incluso cuando el trabajador se haya encontrado en situación de baja por enfermedad durante la totalidad o parte del período de devengo y su incapacidad laboral haya perdurado hasta la finalización de su relación laboral, razón por la cual no haya podido ejercitar su derecho a vacaciones anuales retribuidas.

En la Sentencia KHS AG, de 22 de noviembre de 2011, se aclara que la fijación de un período para el aplazamiento, trascurrido el cual puede declararse extinguido el derecho, es competencia de los Estados miembros. Y en la ANGED, de 21 de junio de 2012, el Tribunal de Justicia recuerda que el derecho a vacaciones anuales retribuidas es un principio del Derecho social de la Unión que también está expresamente reconocido en el artículo 31 de la Carta de los Derechos Fundamentales de la Unión Europea, con el mismo valor jurídico que los tratados. Derecho que no puede ser interpretado de manera restrictiva, siendo su finalidad - «permitir que los trabajadores descansen y dispongan de un período de ocio y esparcimiento»- distinta de la de la baja por enfermedad. Por lo cual, en definitiva, carece de relevancia el momento en que sobrevenga la baja del trabajador, antes o durante las vacaciones.

Merece la pena mencionar que, a su vez, la Sentencia Neidel, de 3 de mayo de 2012, reconoce el derecho a una compensación económica en concepto de vacaciones anuales retribuidas al trabajador en situación de baja por enfermedad durante la totalidad o parte de su período de devengo o su prórroga cuando se produce la extinción del contrato sin llegar a disfrutarlas ${ }^{26}$.

Pues bien, señala ahora la ley española que cuando el período de vacaciones coincida con una incapacidad temporal y el tiempo de baja laboral imposibilite al trabajador disfrutarlas, total o parcialmente, durante el año natural a que corresponden, podrá hacerlo una vez que finalice su incapacidad, siempre que no hayan transcurrido más de dieciocho meses a partir del final del año en que se hayan originado.

Se establece así una regla que obliga a revisar algunas previsiones convencionales que negaban el derecho a la fijación de días alternativos y mejora las que solo permitían el retraso de las vacaciones dentro del año natural ${ }^{27}$. Es este un

26 Para un análisis en profundidad del contenido de estas sentencias, se recomienda la lectura de RodríguezPiñero y Bravo-Ferrer, Miguel (2012). «Derecho a vacaciones y baja del trabajador en la reciente jurisprudencia del TJUE». Relaciones Laborales, n. ${ }^{\circ}$ 13-14.

27 Cfr. los diferentes tipos de cláusulas convencionales, de nuevo, Cabeza Pereiro, Jaime (2008). «Los derechos de conciliación de la vida personal, familiar y laboral de las personas trabajadoras», loc. cit., págs. 242-246. 
terreno, pues, en que se ha asentado el respeto al derecho al tiempo propio por encima de las necesidades organizativas o productivas. Como bien expresaba el voto particular formulado a la previa Sentencia del Tribunal Supremo de 3 de octubre de 2007 — cuando la mayoría de la Sala sostenía aún la tesis contraria-, el tiempo de vacaciones ha de ser tiempo libre o de ocio y algunos proyectos personales se pueden torcer por una incapacidad temporal. La finalidad de las vacaciones es, como se sugería, preservar el desarrollo de la personalidad a través de esos proyectos.

\section{Bibliografía}

Benavente Torres, María Inmaculada (2005). El trabajo a tiempo parcial. Sevilla: Consejo Económico y Social de Andalucía.

Cabeza Pereiro, Jaime (2008). «Los derechos de conciliación de la vida personal, familiar y laboral de las personas trabajadoras», en José Fernando LousAda Arochena (coord.) (2008). El principio de igualdad en la negociación colectiva. Madrid: Ministerio de Trabajo e Inmigración-Comisión Consultiva Nacional de Convenios Colectivos.

Camps Ruiz, Luis Miguel (2012). «Contratación, formación y empleo en el RDL 3/2012», en Ángel Blasco Pellicer et alii (2012). La reforma laboral en el Real Decreto-Ley 3/2012. Valencia: Tirant lo Blanch.

Denia Cuesta, Alfonsa y Guilló Fuentes, María Dolores (2010). «Género y jornada parcial en España: segregación y empleo involuntario», en Antonio Villar (dir.) (2010): Mujeres y mercado laboral en España. Cuatro estudios sobre la discriminación salarial y la segregación laboral. Bilbao: Editorial BriefFundación BBVA.

Ezquerra Escudero, Luis (2006). Tiempo de trabajo: duración, ordenación y distribución. Barcelona: Editorial Atelier.

Luján Alcaraz, J*; González Díaz, F. A. y Ríos Mestre, J* M. (2012) * Medidas para el fomento de la contratación indefinida y la creación de empleo», en Faustino Cavas Martínez (coord.) (2012). La reforma laboral de 2012. Análisis del Real Decreto-Ley 3/2012, de 10 de febrero, de medidas urgentes para la reforma del mercado laboral. Murcia: Ediciones Laborum.

Molina Navarrete, Cristóbal (2012): «De las reformas laborales a un nuevo, e irreconocible, Estatuto del Trabajo Subordinado». Estudios Financieros. Revista de Trabajo y Seguridad Social, n. 348. 
Monereo Pérez, J. L. y Gorelli Hernández, J. (2009). Tiempo de trabajo y ciclos vitales. Estudio crítico del modelo normativo. Granada: Editorial Comares.

Monreal Bringsvaerd, Erik (2005). La jornada de trabajo: ley y convenio colectivo. Madrid.

Ramírez Martínez, Juan Manuel (2012). «Algunos problemas interpretativos planteados por la regulación de la flexibilidad interna en las reformas laborales de 2010 y 2011». Actualidad Laboral, n. ${ }^{\circ} 5$.

Rodríguez-Piñero y Bravo-Ferrer, Miguel (2011). «La difícil coyuntura del Derecho del Trabajo». Relaciones Laborales, $\mathrm{n},{ }^{\circ} 20$.

Rodríguez-Piñero y Bravo-Ferrer, Miguel (2012). «Derecho a vacaciones y baja del trabajador en la reciente jurisprudencia del TJUE». Relaciones Laborales, $\mathrm{n} .^{\circ} 13-14$.

Rodríguez-Piñero y Bravo-Ferrer, Miguel; Valdés Dal-Ré, Fernando y Casas, María Emilia (2012). «La nueva reforma laboral», Relaciones Laborales, $n^{\circ} 5$.

Roqueta Buj, Remedios (2012), «La flexibilidad interna», en Ángel Blasco PeLLICER et alii (2012). La reforma laboral en el Real Decreto-Ley 3/2012. Valencia: Tirant lo Blanch.

Sánchez Trigueros, C. y Fernández Orrico, F. J. (2012)* «Conciliación de la vida familiar y laboral, apoyo al autoempleo y otras medidas», en Faustino Cavas Martínez (coord.) (2012). La reforma laboral de 2012. Análisis del Real Decreto-Ley 3/2012, de 10 de febrero, de medidas urgentes para la reforma del mercado laboral. Murcia: Ediciones Laborum.

VAldés DaL-RÉ, Fernando (2011). «La juridificación del concepto de flexibilidad interna». Relaciones Laborales, $\mathrm{n} .^{\circ} 22$. 